\title{
STABILITY EVALUATION OF CAFFEINE-8-THIOGLICOLIC ACID AMIDES, WITH DETERMINED ANTIHYPOXIC EFFECTS
}

\author{
Javor Mitkov, ${ }^{1}$ Maya Georgieva, ${ }^{2}$ Alexander Zlatkov ${ }^{3}$
}

\begin{abstract}
This study evaluates a series of caffeine-8-thioglycolic acid amides that were synthesized in the study, for signs of possible degradation. The chemical stability of the test compounds was examined under different conditions of $\mathrm{pH}$ and temperature over time. A modified reversed phase-high-performance liquid chromatography method was applied to determine stability and identify possible degradation products. The study identified a new product from oxidative destruction of the test compound through controlled synthesis.
\end{abstract}

UDC Classification: 615.3; DOI: http://dx.doi.org/10.12955/cbup.v5.1107

Keywords: caffeine-8-thioglycolic acid amides, stability, RP-HPLC

\section{Introduction}

Substituted xanthine derivatives are a class of biologically active substances that are well-defined and widely studied in terms of their pharmacological activity as adenosine receptor antagonists, phosphodiesterase inhibitors, and inducers of histone deacetylase activity (Kalla et al., 2006; Lin et al., 2006; Ito et al., 2002). Due to these and several other known factors, this group have become broadly used in medicine not only as agents affecting the central nervous system, but also as active substances in the field of asthma, bronchitis, and chronic obstructive pulmonary diseases and as diuretics, cardiac stimulants, and renal protective agents (Caramori et al., 2003; Dal Piaz \& Giavannoni, 2000; Kiesman et al., 2006).

In developing pharmacologically active substances, the stability of an agent is highly relevant because it relates to the duration in which the product maintains its physical, chemical, microbiological, and toxicological properties within previously established limits (Almeida et al., 2013). To evaluate stability, samples of the designed structures are subjected to conditions of temperature, humidity, and light that are known to accelerate the rate of chemical degradation and thus interfere with the microbiological and toxicological quality of the substances (Baby et al., 2004). A preliminary stability study provides information on the behavior of the synthesized molecules for a given period while subjected to different environmental conditions (Almeida et al., 2013).

The subject of our study is to evaluate the chemical stability of caffeine-8-thioglycolic acid amides (that were synthesized in the study) under certain conditions of temperature, $\mathrm{pH}$, and presence and absence of air.

\section{Materials and Methods}

Chemistry

Melting points were determined in Celsius $\left({ }^{\circ} \mathrm{C}\right)$ using an electrothermal apparatus (B-535, BÜCHI Switzerland) in an open capillary tube and uncorrected values recorded. Using Fourier transform infrared spectroscopy (FTIR), the spectra $400-4000 \mathrm{~cm}^{-1}$ were recorded using a Nicolet ${ }^{\mathrm{TM}} \mathrm{iS}^{\mathrm{TM}} 10 \mathrm{FT}$ IR spectrometer (Thermo Fisher Scientific) with an attenuated total reflectance (ATR). The ${ }^{1} \mathrm{H}$ - and ${ }^{13} \mathrm{C}$-Nuclear Magnetic Resonance (NMR) spectra were recorded at ambient temperatures, with dimethyl sulfoxide- $\mathrm{d}_{6}\left(\mathrm{DMSO}-\mathrm{d}_{6}\right)$ as the solvent, using a Bruker-250 WM $(250 \mathrm{MHz})$ spectrometer (Germany). The ${ }^{1} \mathrm{H}-\mathrm{NMR}$ spectra were measured with solutions of approximately $0.03 \mathrm{M}$ and the ${ }^{13} \mathrm{C}-$ NMR spectra with solutions of approximately $0.05 \mathrm{M}$, both using DMSO- $\mathrm{d}_{6}$ as solvent, and chemical shifts were expressed as $\delta$ values in parts per million ( $\mathrm{ppm}$ ) against tetramethylsilane (TMS) as an internal standard. Splitting patterns were designed as follows: s, singlet; d, doublet; t, triplet; and m, multiplet. Mass spectra were recorded using a liquid chromatography-mass spectrometry (LCMS)/MS Thermo Scientific Q Exactive Plus - Dionex 3000 Rapid Separation liquid chromatography (RSLC) system. Preparative thin layer chromatography (TLC) was performed using a DC-Alufolien

\footnotetext{
${ }^{1}$ Medical University, Faculty of Pharmacy, Department of Pharmaceutical Chemistry, Bulgaria, javor.mitkov@abv.bg

${ }^{2}$ Medical University, Faculty of Pharmacy, Department of Pharmaceutical Chemistry, Bulgaria, georgm@mail.bg

${ }^{3}$ Medical University, Faculty of Pharmacy, Department of Pharmaceutical Chemistry, Bulgaria, alex.zlatkov@gmail.com
} 
Kieselgel 60 F254, with $0.20 \mathrm{~mm}$ (Merck, Germany) sheets in the mobile phase: chloroform-acetoneethanol $(3: 3: 4 ; \mathrm{v} / \mathrm{v})$. The spots were detected at UV $254 \mathrm{~nm}$. Elemental analyses were performed by the microanalytical laboratory of the Faculty of Pharmacy (Medical University-Sofia) using a EuroEA3000-Single analyzer (EuroVector S.p.A, Milan). Synthetic grade chemicals procured from Merck, Germany, were used for the synthesis of the target compounds, as received. All solutions were dried over anhydrous sodium sulfate and evaporated on a BÜCHI rotary evaporator at reduced pressure. The given yields were for the analytically pure product. No efforts were made to optimize the yields. „Nomenclature" was generated by using structure-to-name and name-to-structure algorithms of the software, ChemBioDraw Ultra 11.0 (CambridgeSoft).

\section{Synthesis of N-(2-phenylethyl-2-((1,3,7-trimethyl-2,6-dioxo-2,3,6,7-tetrahydro-1H-purine-8-yl)- sulfanyl)-acetamide, 3}

A solution of $3.87 \mathrm{~g}(0.01 \mathrm{~mol})$ of a caffeine-8-thioglycolic acid amide $2 \mathrm{~b}$, (Figure 1) in $50 \mathrm{ml}$ of methylene chloride was placed in a three-necked reaction flask equipped with a thermometer and a reflux condenser. The reaction flask was placed in a water bath $\left(\right.$ at $\left.10^{\circ} \mathrm{C}\right)$ with $1.9 \mathrm{~g}(0.011 \mathrm{~mol}) \mathrm{m}$ Chloroperoxybenzoic acid ( $m$-CPBA), dissolved in $20 \mathrm{ml}$ of methylene chloride, which was added slowly while stirring the solution. The temperature of the reaction mixture was kept within the range $10-15{ }^{\circ} \mathrm{C}$, with ice pieces added to the bath when necessary to maintain this range. After complete addition of $m$-CPBA, the reaction mixture was stirred at room temperature for one hour (controlled using the TLC in system 2). Then, the solvent was removed under reduced pressure, and the crude product was recrystallized from methanol. Yield $3.06 \mathrm{~g}(76 \%)$ m.p. $187-189{ }^{\circ} \mathrm{C}$; FT-IR (ATR) 3275 $(\mathrm{vNH}), 3102(\mathrm{vCH}-$ aromatic), 1704 ( $\mathrm{vCO}$ - xanthine), 1668 with shoulders at 1601 and 1627 ( $\mathrm{vCO}$ xanthine, $v \mathrm{CO}$ - amide $\mathrm{I}, v \mathrm{C}=\mathrm{N}, v \mathrm{C}=\mathrm{C}$ - aromatic $), 1552$ и $1534(\mathrm{vC}=\mathrm{C}-$ xanthine, $v \mathrm{C}=\mathrm{C}-$ aromatic, $v \mathrm{NH}$ - amide II), $1062(\mathrm{vSO}), 754$ and $746\left(\mathrm{vCH}-\right.$ aromatic). The ${ }^{1} \mathrm{H}-\mathrm{NMR}: 7.28-7.10(\mathrm{~m}, 5 \mathrm{H}$, aromatic); $4.81\left(\mathrm{~s}, 2 \mathrm{H}, \mathrm{CH}_{2}\right) ; 3.80\left(\mathrm{~s}, 3 \mathrm{H}, \mathrm{CH}_{3}\right) ; 3.49\left(\mathrm{~s}, 3 \mathrm{H}, \mathrm{CH}_{3}\right) ; 3.32\left(\mathrm{~s}, 3 \mathrm{H}, \mathrm{CH}_{3}\right) ; 3.27\left(\mathrm{~d}, 2 \mathrm{H}, \mathrm{CH}_{2}\right.$, $\mathrm{J}=6.7 \mathrm{~Hz}) ; 2.82\left(\mathrm{~d}, 2 \mathrm{H}, \mathrm{CH}_{2}, \mathrm{~J}=6.7 \mathrm{~Hz}\right) ;{ }^{13} \mathrm{C}-\mathrm{NMR}: 163.9(\underline{\mathrm{CO}}-\mathrm{NH}) 160.4\left(\mathrm{C}^{8}{ }_{\text {xanth }}\right) ; 154.7\left(\mathrm{C}^{6}{ }_{\text {xanth }}\right.$ $\mathrm{CO}) ; 151.4\left(\mathrm{C}^{2}\right.$ xanth $\left.\mathrm{CO}\right) ; 139.1,128.5,128.7,129.9\left(6 \times \underline{\mathrm{C}}\right.$ aromatic ring); 148.8 ( $\underline{\mathrm{C}}^{4}$ xanth); 107.1 $\left(\mathrm{C}^{5}\right.$ xanth $) ; 59.7\left(\mathrm{SO}-\mathrm{CH}_{2}\right), 41.4\left(\mathrm{NH}-\mathrm{CH}_{2}\right) ; 35.75\left(\mathrm{CH}_{2}-\mathrm{Ph}\right.$ side chain $), 32.5\left(\mathrm{~N}^{7}\right.$ xanth $\left.\mathrm{CH}_{3}\right), 29.8\left(\mathrm{~N}^{3}\right.$ xant $\left.\mathrm{CH}_{3}\right), 27.9\left(\mathrm{~N}^{1}\right.$ xanth $\left.\mathrm{CH}_{3}\right) ; \mathrm{MS}$ m/z: 167 (100), $445(\mathrm{M}+1)$. Microanalysis: Calc. C 53.59\%, H 5.25\%, N $17.36 \%$, S 7.95\%; Found C 53.55\%, H 5.25\%, N $17.39 \%$, S 7.98\%.

\section{Instrumentation and Chromatographic Conditions}

The chromatographic analysis was performed on a liquid chromatography (LC) system (LC-10ADvp, Shimadzu Kyoto, Japan), equipped with temperature control unit (CTO-10ASvp, Shimadzu Kyoto, Japan), an isocratic pump, and a UV-VIS detector (SPD-10AVvp, Shimadzu, Kyoto, Japan). The following chromatographic columns: TRACER EXCEL ${ }^{\mathrm{TM}}$ (Teknokroma, Spain) Reverse-Phase (RP) 18 (ODS $250 \mathrm{~mm} \times 4.6 \mathrm{~mm}, 5.5 \mu \mathrm{m}$ ) and Luna ${ }^{\circledR}$ (Phenomenex, California) $5 \mu \mathrm{C} 18$ (2) 100A (4.6 i.d. $\times 250 \mathrm{~mm}$ ), were chosen for method validation and stability testing. The UV-VIS detector was set to wavelengths of 240 and $254 \mathrm{~nm}$. Isocratic elution with a flow rate of $2.0 \mathrm{ml} \mathrm{min}^{-1}$ was used. A column oven was conditioned at $20^{\circ} \mathrm{C}$. The injection volume was $20 \mu \mathrm{l}$ with an analysis time of 15 minutes. The following chromatographic procedure was developed for obtaining best separation for the analyzed model compound from its degradation products, based on the application of a polar mobile phase for isocratic flow with no additional buffering (Table 1).

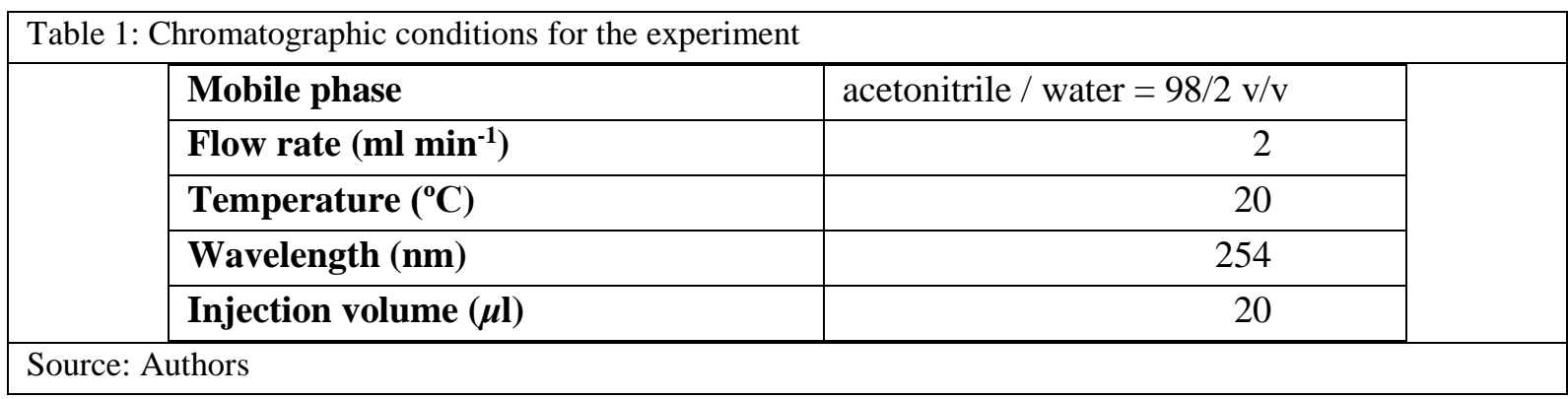

Preparation of the Mobile Phase

In a 1-litre volumetric flask, a 98/2 v/v solvent mixture of acetonitrile/water was prepared. The obtained solution was degassed through a $45-\mu \mathrm{m}$ membrane filter. 
Preparation of Buffer $\mathrm{pH} 1.0$

A $0.01 \mathrm{~mol} \mathrm{l}^{-1} \mathrm{HCl}$ solution was prepared with a $\mathrm{pH}$ of 1.0 .

Preparation of Buffer pH 12.0

A $0.01 \mathrm{~mol} \mathrm{l}^{-1} \mathrm{NaOH}$ solution was prepared with a $\mathrm{pH}$ of 12.0 .

\section{Results and Discussion}

The test products were synthesized according to a procedure described elsewhere (Mitkov et al., 2007, 2010; Figure 1).

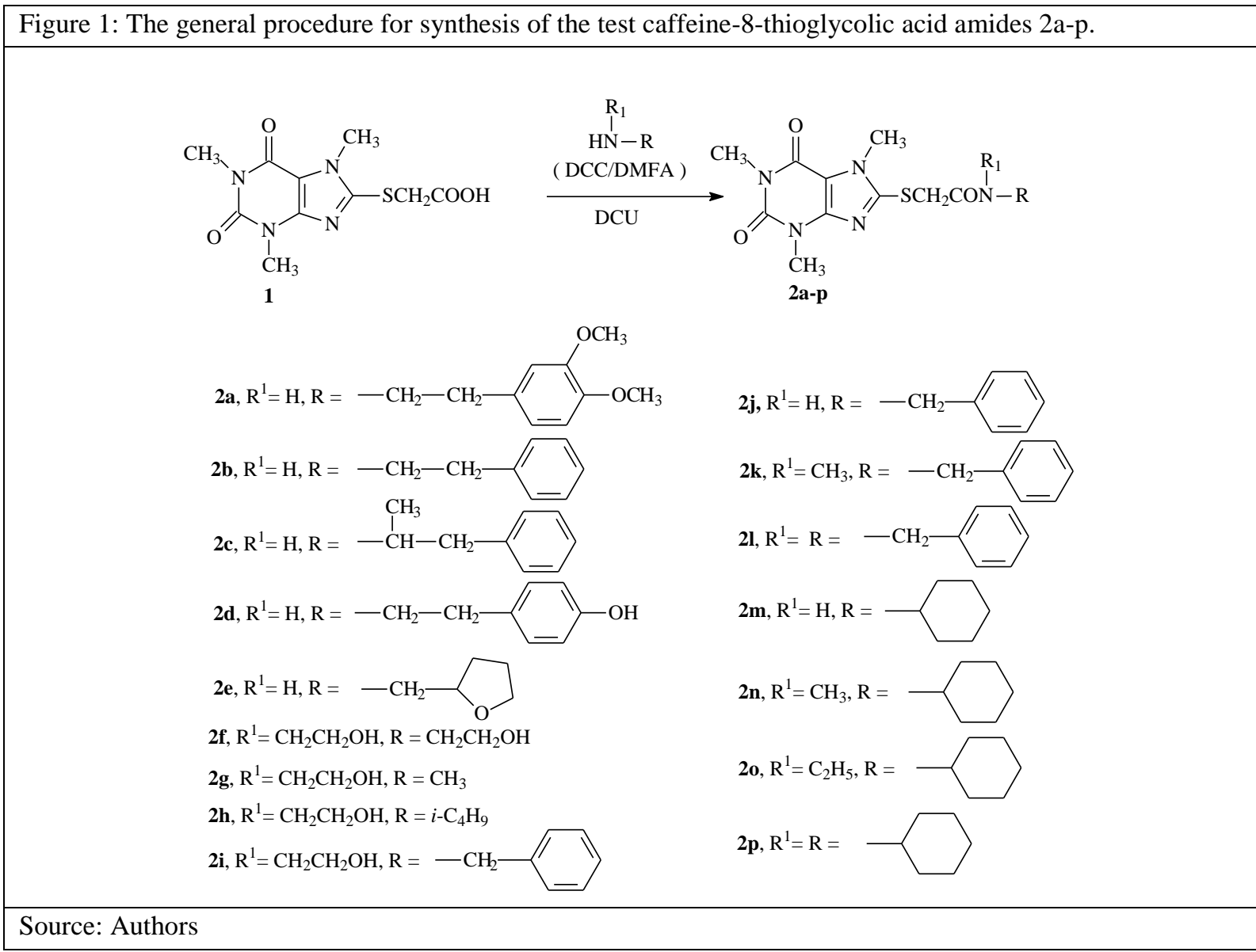

\section{Evaluation of the Stability of the Synthesized Caffeine-8-Thioglycolic Acid Amides}

To study the properties of the resulting amide derivatives, the behavior of the structures was followed for degradation processes at different values of $\mathrm{pH}$ over time.

For this purpose, compound $2 \mathrm{~b}$ (Figure 1) was selected as a model structure, since it was the least spatially hindered amide. The lack of shielding substituents indicated that this amide would be the most susceptible to hydrolysis.

Based on the synthesis approach for obtaining the desired caffeine-8-thioglycolic acid amides and the chemical properties of the amide group, a hydrolytic cleavage of the amide bond and formation of the first caffeine-8-thioglycolic acid was expected.

The analyzed product, $2 \mathrm{~b}$, and the expected caffeine-8-thioglycolic acid, were chromatographically analyzed, individually as well as in a model mixture, to validate the applicability of the RP-Highperformance liquid chromatography (RP-HPLC) method modified by this study.

\section{Validation of the Modified RP-HPLC Analytical Procedure}

The method was validated according to guidelines of the International Concil for Harmonisation (ICH) of Technical Requirements for Pharmaceuticals for Human Use (ICH, Q2(R1), Harmonised Tripartite Guideline, 2005). The system suitability (i.e., repeatability of retention times and areas, the number of theoretical plates, and resolution), precision, linearity, accuracy, and selectivity were evaluated during 
the method validation (Table 2). The test products were evaluated for accuracy, precision, and selectivity.

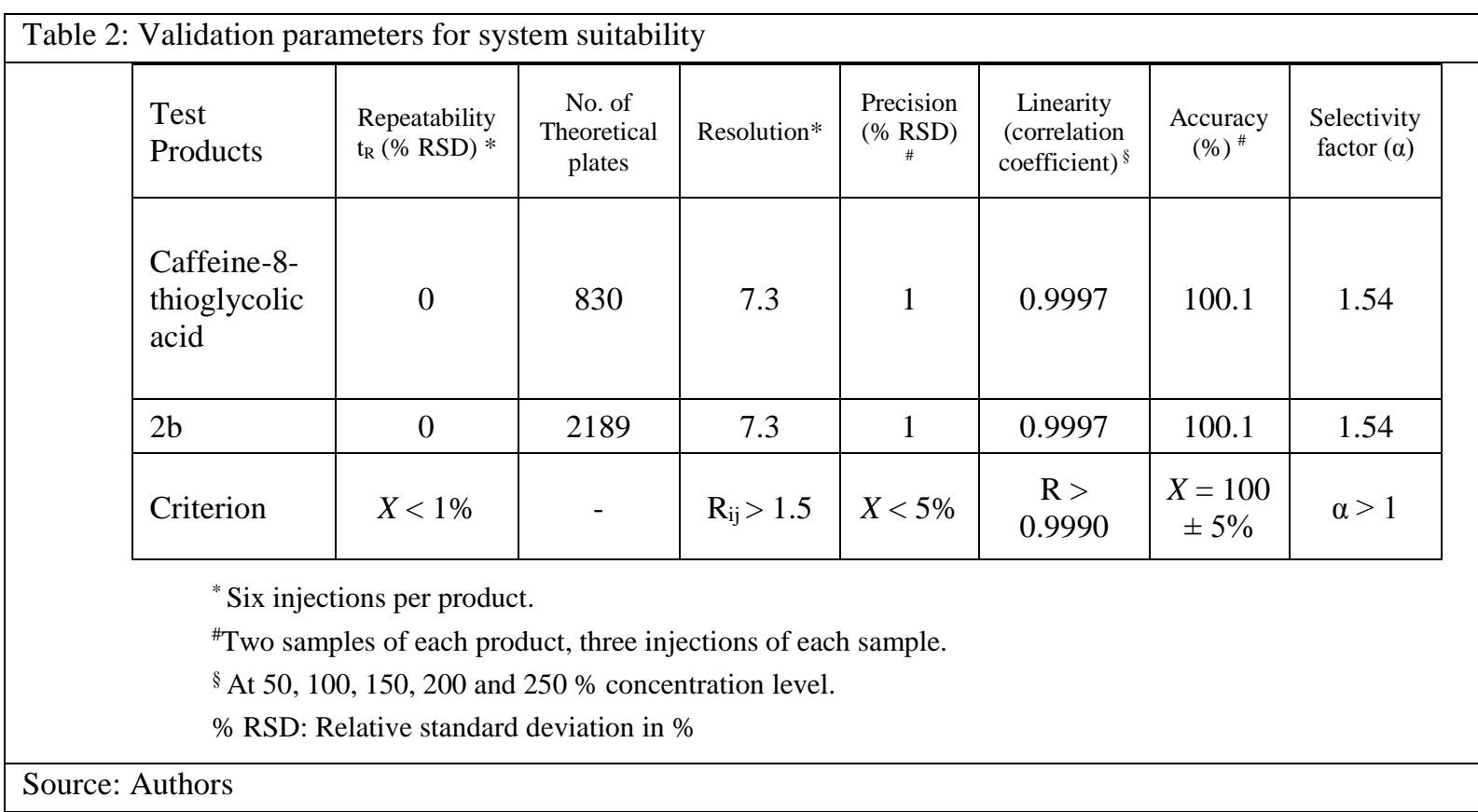

\section{Precision}

Six sample solutions (three of Caffeine-8-thioglycolic acid and three of $2 b$ ) were prepared and each sample was injected three times. The final results were reported as relative standard deviation (\% RSD) of the ratios of the peak area of the tested compound.

Linearity

A 5-point calibration curve was created, covering the concentration range of $2 \mathrm{~b}$, from $0.02 \mathrm{mg} \mathrm{ml}^{-1}$ to $0.1 \mathrm{mg} \mathrm{ml}^{-1}$. A linear regression of the calibration data was performed. The correlation coefficient of linearity was 0.998 (Figure 2), which indicated a high correlation between the peak areas and the range of concentrations studied.

Figure 2: Correlation coefficient of linearity indicating the high correlation between the peak areas and the range of concentrations studied

\begin{tabular}{|l|r|r|r|r|}
\hline & 1400000 \\
1200000 \\
1000000 \\
\end{tabular}

Accuracy

A solution of Caffeine-8-thioglycolic acid and a stock solution of compound $2 b$ were prepared. From these, six subsamples (three of the Caffeine-8-thioglycolic acid and three of the stock solution), allowed each solution to be injected onto the column three times. Accuracy is reported as a parameter recovery with relative standard deviations. 


\section{Selectivity}

The selectivity was determined by the corresponding selectivity factor $(\alpha)$, measured as a ratio of the retention factors $(\mathrm{k})$ of the two peaks in question and visualized as the distance between the apices of the two peaks.

\section{Determination of Stability at Different $\mathrm{pH}$}

\section{Chemical Stability}

By definition, chemical stability is the tendency of a substance to sustain changes or decay caused by internal reactions or effects of air, humidity, heat, light, pressure, or other external factors. The compound presented in this paper had been stored for six months at room temperature with access to air and light. The physical and chemical properties of the compound were determined to be unchanged under these conditions. Hence, the test compound was considered chemically stable.

An important factor influencing the performance of the molecules in an organism is the hydrolytic stability of the molecules under the following conditions: temperature of $38^{\circ} \mathrm{C}$ and $\mathrm{pH}$ of 1.0 and 12.0 (ICH Guidance for industry, Q2A (R2), 2003).

\section{Hydrolytic Stability Study at a Temperature of $38{ }^{\circ} \mathrm{C}$, $\mathrm{pH}$ of 1.0 and 12.0, and in Oxygen-Free} Media

For evaluating stability, corresponding buffer solutions of the test compound, $2 \mathrm{~b}$, were prepared to obtain the desired $\mathrm{pH}$ values. A 10-mg sample of the model compound was weighed and dissolved under oxygen-free conditions in corresponding buffers of $\mathrm{pH} 1.0$ and 12.0, respectively. The obtained solutions were stirred while being maintained at $38^{\circ} \mathrm{C}$ for a total of $1440 \mathrm{~min}$ ( 24 hours) using liquid nitrogen to assure the absence of air. Aliquots of $20 \mu \mathrm{l}$ of the analyzed solutions were drawn at 30minute intervals and injected into the apparatus. The corresponding chromatograms were obtained (Figures 3-4).

Stability Determination of Compound $2 \mathrm{~b}$ at $\mathrm{pH} 1.0$

A 10-mg sample of the model compound was weighed and dissolved in $100 \mathrm{ml}$ of $0.01 \mathrm{~mol} \mathrm{l}^{-1} \mathrm{HCl}$ (pH 1.0). This solution was stirred at $38^{\circ} \mathrm{C}$ for a total time of 1440 min using liquid nitrogen to assure the absence of air. Aliquots of $20 \mu \mathrm{l}$ samples were drawn at 30-minute intervals and injected into the RP-HPLC system. Figure 3 presents a representative chromatogram.

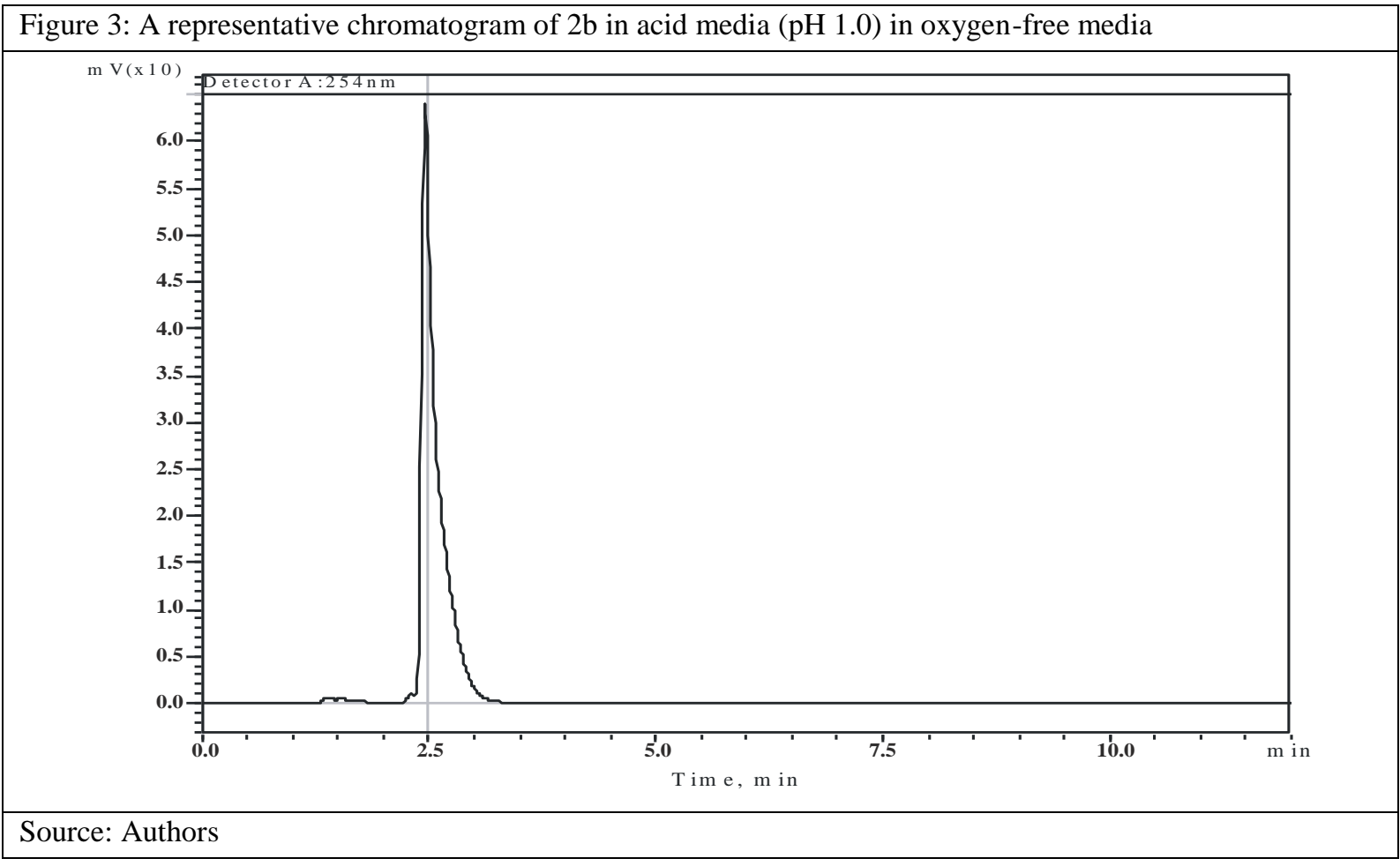

As presented, no additional peaks were visible for the total $1440 \mathrm{~min}$ evaluation period under these conditions. 
Stability Determination of Compound $2 \mathrm{~b}$ at $\mathrm{pH} 12.0$

A 10-mg sample of the model compound was weighed and dissolved in $100 \mathrm{ml}$ of $0.01 \mathrm{~mol} \mathrm{l}^{-1} \mathrm{NaOH}$ (pH 12.0). The obtained solution was stirred at $38^{\circ} \mathrm{C}$ for a total time of $1440 \mathrm{~min}$ using liquid nitrogen to assure the absence of air. Aliquots of $20 \mu \mathrm{l}$ samples were drawn at 30-min intervals and injected into the RP-HPLC system. Figure 4 displays a representative chromatogram.

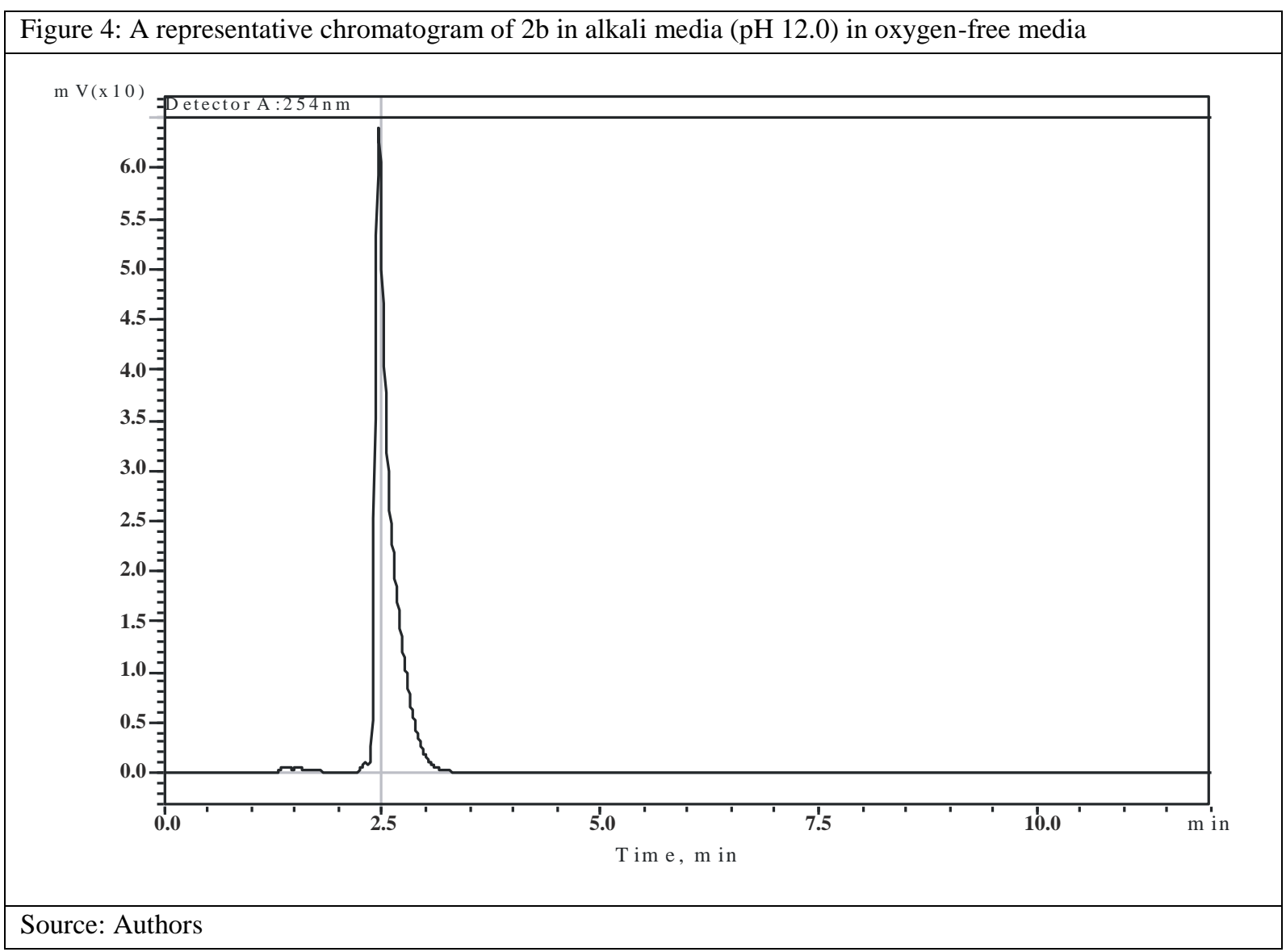

As presented, no additional peaks were visible for the total 1440 min evaluation period under these conditions.

These results lead to the conclusion that in both media no hydrolysis occurred within 24 hours. These evaluations were conducted in oxygen-free media.

To identify the influence of oxygen on the stability of the target product, evaluations were performed in oxygenated media. The chosen model compound was incubated in both acid and alkali media for 1440 min using the above-discussed conditions, as follows: A 10-mg sample of the model compound was weighed and dissolved in corresponding buffers of $\mathrm{pH} 1.0$ and 12.0, respectively. The obtained solutions were temperature-controlled and stirred in oxygenated media at $38{ }^{\circ} \mathrm{C}$ for a total time of $1440 \mathrm{~min}$ ( 24 hours). Aliquot samples of $20 \mu \mathrm{l}$ of the analyzed solutions were drawn at 30-minute intervals and injected into the apparatus. The corresponding chromatograms were obtained (Fig.5\&6).

Stability Determination of Compound $2 \mathrm{~b}$ at $\mathrm{pH} 1.0$ in the Presence of Air

Fig. 5 shows the effects of incubating the test compound in acid media, $\mathrm{pH} 1.0$, in the presence of air.

An unidentified peak with a retention time close to that of the analyzed structure was observed under the test conditions. The calculated relative retention of the unidentified peak and that of $2 b$ were close to 1 . This showed that no separation was achieved under the applied chromatographic conditions.

Stability Determination of Compound $2 \mathrm{~b}$ at $\mathrm{pH}$ of 12.0 in the Presence of Air

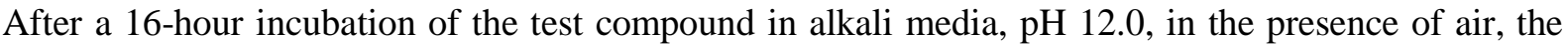
same results to those for the acid media presented. Again, no separation was achieved.

In an attempt to separate and identify the new product, the chromatographic procedure was modified, by changing the mobile phase as shown in Table 3 . 


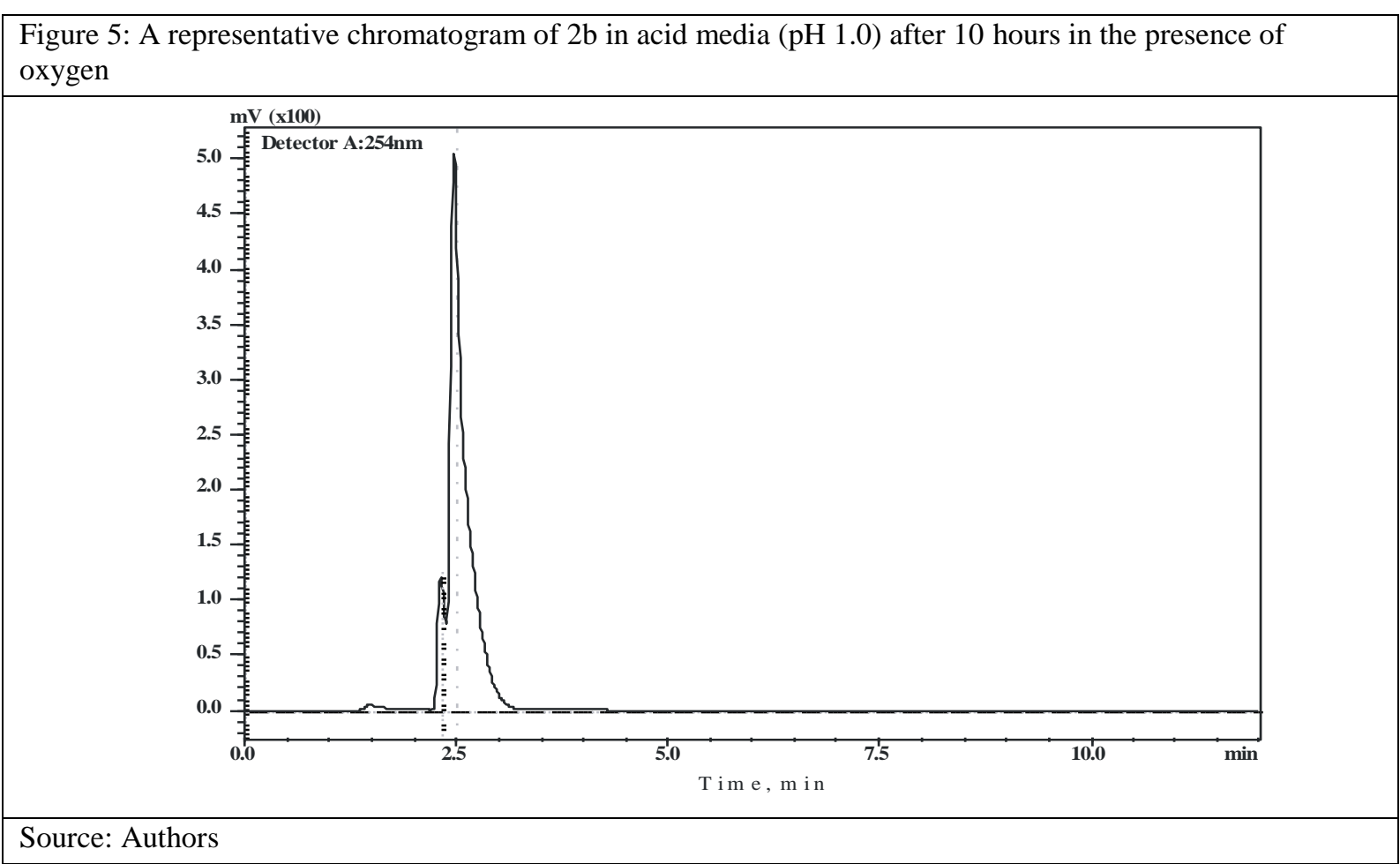

Table 3: Modified chromatographic conditions to separate and identify a new product in the study

\begin{tabular}{|l|c|c|c|c|}
\hline Mobile Phase & $\begin{array}{c}\text { Flow rate } \\
\left(\mathbf{m l ~ m i n}^{-1}\right)\end{array}$ & $\begin{array}{c}\text { Temperature } \\
\left({ }^{\mathbf{o}} \mathbf{C}\right)\end{array}$ & $\begin{array}{c}\text { Wavelength } \\
(\mathbf{n m})\end{array}$ & $\begin{array}{c}\text { Injection volume } \\
(\boldsymbol{\mu} \mathbf{L})\end{array}$ \\
\hline acetonitrile / water (98/2 v/v) & 2 & 20 & 254 & 20 \\
\hline methanol / water (75/25 v/v) & 2 & 20 & 254 & 20 \\
\hline
\end{tabular}

Source: Authors

In applying the new conditions, a good separation was achieved, as shown in Figure 6.

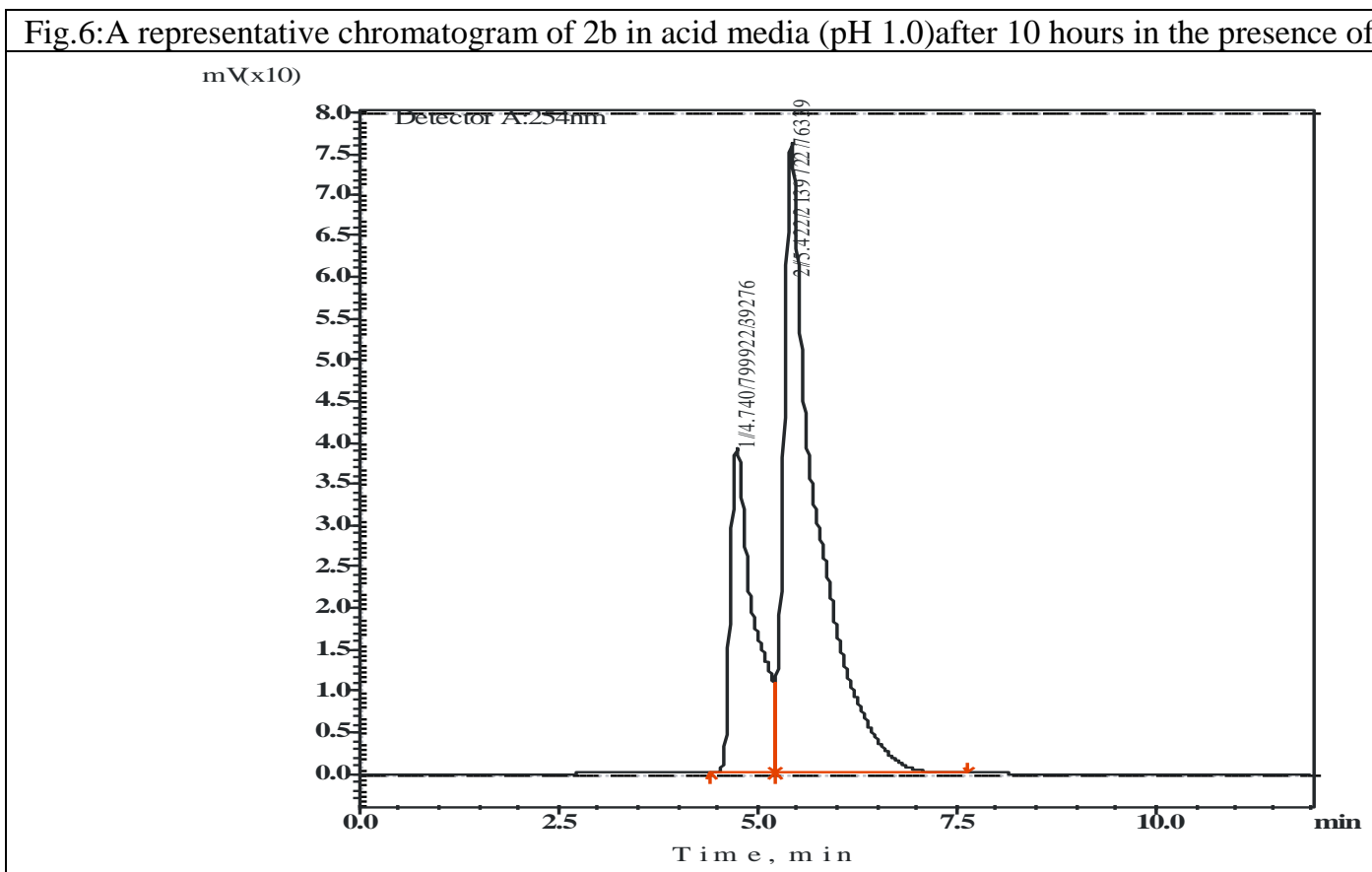

Source: Authors 
Based on the identified degradation product having a similar chromatographic behavior to that found for $\mathbf{2 b}$, it appears the targeted amides are oxidized through exposure to air into corresponding sulfines. This process is similar to the derivation of corresponding esters from caffeine-8-thioglycolic acid (Mitkov et al., 2007).

To demonstrate this, we synthesized the probable sulfine product, according to the procedure, summarized in Figure 7.

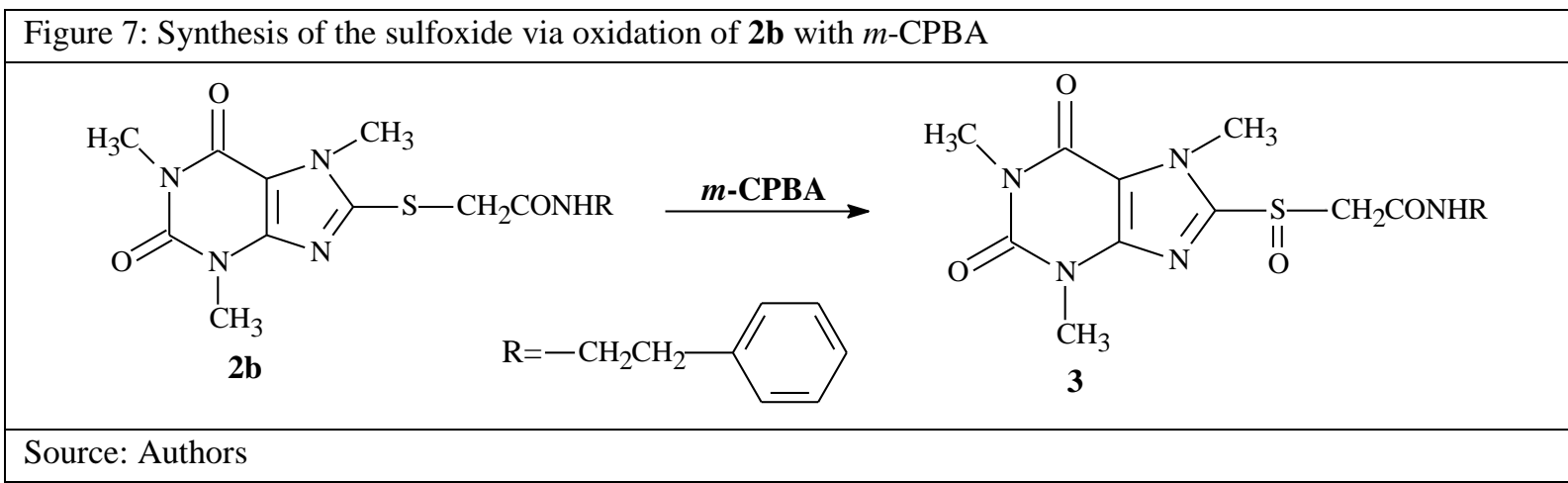

The synthesized compound was found to be freely soluble in chloroform, dichloromethane, Dimethylformamide (DMF), and DMSO, but insoluble in non-polar solvents, such as n-hexane. The structure of the synthesized S-oxide was confirmed by FTIR, ${ }^{1} \mathrm{H}-$ and ${ }^{13} \mathrm{C}-\mathrm{NMR}$, MS spectra, and elemental analysis. The results were consistent with the assigned structure. The ${ }^{1} \mathrm{H}-\mathrm{NMR}$ spectrum of the compound revealed the signals of the respective protons, which were verified by chemical shifts, multiplicities, and coupling constants.

The chemical shifts of the protons and carbon atoms, registered by ${ }^{1} \mathrm{H}-$ and ${ }^{13} \mathrm{C}-\mathrm{NMR}$ spectra, were compared with simulated values (Banfi et al., 2008, Andrés et.al., 2011, Aires-de-Sousa et al., 2002). A strong correlation between the registered and computed values was observed.

The obtained product was analyzed individually and in a model mixture with the initial $2 \mathrm{~b}$. Figure 8 shows the result of the analysis.

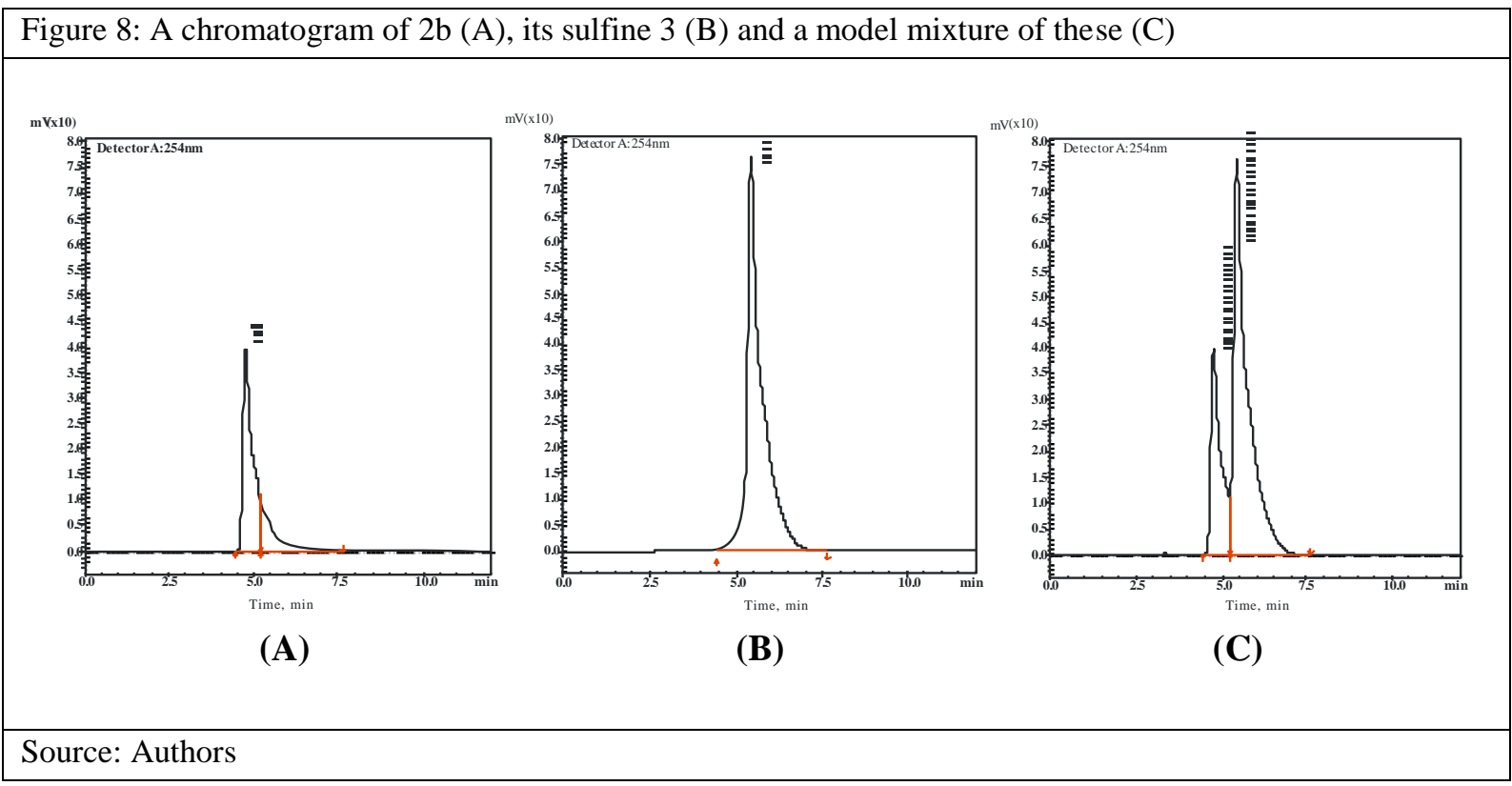

An unidentified peak as a result of the degradation under acid $(\mathrm{pH} 1.0)$ and alkali $(\mathrm{pH} 12.0)$ media in the presence of oxygen is shown at the same retention time as that for the sulfine product (B; Fig.8).

\section{Conclusion}

The stability of an amide derivative of caffeine-8-thiogyolic acid, $\mathbf{2} \mathbf{b}$, was determined under acid ( $\mathrm{pH}$ 1.0) and alkali ( $\mathrm{pH} 12.0)$ conditions, at a temperature of $38{ }^{\circ} \mathrm{C}$ and in the presence and absence of oxygen. A sulfine degradation product resulted in both $\mathrm{pH}$ condition, in the presence of oxygen only. 
The structure of the degradation product was determined through controlled synthesis. The findings lead to the conclusion that the only possible degradation process for the test structure is via oxidation at $38^{\circ} \mathrm{C}$ in strong acid and alkali media with exposure to air. We propose this to be the most probable metabolic process of the target compound.

\section{References}

Aires-de-Sousa, M. Hemmer, J. Gasteiger. (2002). "Prediction of 1H NMR Chemical Shifts Using Neural Networks". Analytical Chemistry. 74(1), 80-90

Almeida, Mariana Mandelli; Bou-Chacra, Nádia A; Conte, Juliana Denise; Kaneko, Telma Mary; Baby, André Rolim; Velasco, Maria Valéria Robles. Evaluation of Physical and Chemical Stability of Nanostructured Lipid Carries Containing Ursolic Acid in Cosmetic Formulation. (2013). Journal of Applied Pharmaceutical Science. 3 (1), 5-8

Andrés M. Castillo, Luc Patiny and Julien Wist. (2011). Fast and Accurate Algorithm for the Simulation of NMR spectra of Large Spin Systems. Journal of Magnetic Resonance.

Baby AR, Maciel CPM, Zague V, Kaneko TM, Consiglieri VO, Velasco MVR. (2004). Estabilidade de Produtos de Aplicação tópica. Int J Pharm Comp. 6,130-139

Banfi, D.; Patiny, L. (2008). www.nmrdb.org: Resurrecting and processing NMR spectra on-line Chimia, 62(4), $280-281$.

Caramori, G.; Adcock, I. (2003). Pharmacology of airway inflammation in asthma and COPD. Pulm. Pharmacol. Ther. 16(5), 247-277.

Dal Piaz, V.; Giavannoni, M. P. (2000). Phosphodiesterase 4 inhibitors, structurally unrelated to Rolipram, as promising agents for the treatment of asthma and other pathologies. Eur. J. Med. Chem. 35(5), 463-480;

Ito, K.; Lim, S.; Caramori, G.; Cosio, B.; Chung, K. F.; Adcock, I. M.; Barnes, P. J. (2002). A molecular mechanism of action of theophylline: Induction of histone deacetylase activity to decrease inflammatory gene expression. Proc. Natl. Acad. Sci. U.S.A. 99(13), 8921-8926.

International Council for Harmonisation, Expert Working Group, (2005). Validation of Analytical Procedures: Text and Methodology Q2(R1), Available from:

https://www.ich.org/fileadmin/Public_Web_Site/ICH_Products/Guidelines/Quality/Q2_R1/Step4/Q2_R1_Guideline.pdf

ICH. Guidance for industry Q1A(R2) Stability testing of new drug substances and products. 2003; Available from: https://www.fda.gov/downloads/Drugs/GuidanceComplianceRegulatoryInformation/Guidances/UCM073369.pdf

Kalla, R. V.; Elzein, E.; Perry, T.; Li, X.; Palle, V.; Varkhedkar, V.; Gimbel, A.; Maa, T.; Zeng, D.; Zablocki, J. (2006). Novel 1,3-Disubstituted 8-(1-benzyl-1H-pyrazol-4-yl) Xanthines: High Affinity and Selective A2B Adenosine Receptor Antagonists J. Med. Chem. 49(12), 3682-3692.

Kiesman, W. F.; Zhao, J.; Conlon, P. R.; Dowling, J. E.; Petter, R. C.; Lutterodt, F.; Jin, X.; Smits, G.; Fure, M.; Jayaraj, A.; Kim, J.; Sullivan, G.; Linden, J. (2006). Potent and Orally Bioavailable 8-Bicyclo[2.2.2]octylxanthines as Adenosine $A_{1}$ Receptor Antagonists. J. Med. Chem. 49(24), 7119-7131

Lin, R.-Y.; Wu, B.-N.; Lo, Y.-C.; An, L.-M.; Dai, Z.-K.; Lin, Y.-T.; Tang, C.-S.; Chen, I.-J. (2006). A Xanthine-Based Epithelium-Dependent Airway Relaxant KMUP-3 (7-[2-[4-(4-Nitrobenzene)piperazinyl]ethyl]-1,3- dimethylxanthine) Increases Respiratory Performance and Protects against Tumor Necrosis Factor- $\alpha$-Induced Tracheal Contraction, Involving Nitric Oxide Release and Expression of cGMP and Protein Kinase GJ. Pharmacol. Exp. Ther. 316(2), 709-717;

Mitkov, J., Danchev, N., Nikolova, I., Zlatkov, A., (2007). Synthesis and brain antihypoxic activity of some aliphatic and arylaliphatic amides of caffeine-8-thioglycolic acid Acta Pharm. 57, 361-370.

Mitkov, J., Nikolova, L., Nikolova, I., Danchev, N., Zlatkov A., (2010). Synthesis and brain antihypoxic activity of some aminoalcoholic derivatives of caffeine-8-thioglycolic acid Comptes Rendus de L'Academie Bulgare des Sciences. 63(7), $1075-1082$

Mitkov, J., Pencheva, I., Zlatkov Al. (2007). Synthesis and chromatographic investigations of some ester derivatives of caffeine-8-thioglycolic acid. Full Paper, $13^{\text {th }}$ Pan-Hellenic Pharmaceutical Congress, May 12-14, Athens, Greece. Abstract published in: Eur. J. Drug Metabol. Pharmacokinetic. Special issue. 